\title{
LA INFLUENCIA DE LAS OPERACIONES MILITARES EN SIRIA EN EL ESTADO DE LA SEGURIDAD INTERNACIONAL EN LA ESFERA MILITAR Y SOCIAL
}

\author{
Kamila Kasperska-Kurzawa ${ }^{1}$
}

SumarıO: I. Introducción. II. Orígenes del Conflicto Sirio. III.La Influencia del Conflicto Sirio en el Estado de la Seguridad Militar Mundial. IV. El Impacto del Conflicto Sirio en el Estado de la Seguridad Social a Nivel Internacional. V. Conclusiones.

VI. Bibliografía y Fuentes Consultadas.

\section{Resumen}

Las operaciones militares en Siria están involucrando enormes fuerzas, por un lado las pertenecientes a las capacidades militares del ejército de Assad, y por otro a las fuerzas religiosas que aspiran a derribar su régimen. Con independencia de la guerra civil, desarrollándose desde el 2011, actúan también las fuerzas pro- Assad, y las unidades integradas en el Cuerpo de la Guardia Revolucionaria Islámica ${ }^{2}$. Además de las acciones militares en el territorio de Siria e Irak, dirigidas por las fuerzas de la coalición de los países occidentales lideradas por Estados Unidos,. En el Norte de Siria, , las operaciones contra el Estado islámico son llevadas a cabo por fuerzas kurdas La gran cantidad de participantes en estas acciones conduce con frecuencia a conflictos de intereses. Como ejemplo, el derribo de un avión ruso por fuerzas turcas, que generó un potencial riesgo de un conflicto militar que podría englobar a la totalidad de Medio Oriente, así como poner en peligro la estabilidad no solamente de la región mencionada, sino también convertirse en un conflicto global entre Rusia y la Organización del Tratado del Atlántico Norte (OTAN). La situación en Siria está lejos de la estabilización y en cualquier momento puede convertirse en la chispa de un conflicto de amplia dimensión internacional.

Palabras Clave: Siria, Estado Islámico, política internacional.

\footnotetext{
${ }^{1}$ Kamila Kasperska-Kurzawa es Doctora en Politología por la Universidad Marie Curie-Sklodowska en Lublin y es Profesora en la Facultad de Derecho y Administración de la Universidad de Opole. Su tesis doctoral versó sobre el crimen organizado internacional. Correo electrónico: kamilakasperska@onet.pl

${ }^{2}$ CGRI - El Cuerpo de la Guardia Revolucionaria Islámica. En octubre de 2015 en Alepo fallecieron 30 oficiales de CGRI, entre ellos tres generales, comandantes de batallones, capitanes y tenientes, así como un piloto.
} 


\title{
The influence of military operations in Syria on the state of international security in the militar and social sphere
}

\begin{abstract}
Armed forces in Syria involve enormous forces, which on the one hand belong to the armed forces of Assad, and on the other hand are the forces of the religions seeking to overthrow his regime. In this country, regardless of the actual civil war that has been taking place since 2011, Assad's forces, such as the units of the Russian army, include mainly air forces. In Syria, the units of the Islamic Revolutionary Guard Corps also operate. In addition, military operations in Syria and Iraq lead the coalition forces of Western states under the command of the United States, which use aviation to continually bombard the so-called "Islamic State". In the north of Syria, in the region of Aleppo, the Kurdish forces are acting against the Islamic State. These forces have recently been systematically attacked by Turkish troops, which, as part of the fight against the Islamic State, also bombard and bombard Kurdish groups. The presence of such a large number of participants leads to frequent conflicts of interest. As an example, the Turkish aircraft can be shot down by the Turkish forces, resulting in the threat of a military conflict that could cover the entire Middle East and threaten the stability of not only the Middle East but also the global conflict between Russia and North Atlantic Treaty Organization (NATO). The situation in Syria is still far from stable and at any moment can be a hotbed of conflict of a wider international dimension.
\end{abstract}

Key Words: Syria, Islamic State, international policy.

\section{Introducción}

A finales del siglo $X X$ y durante las dos primeras décadas del siglo $X X I$ se registró un incremento de la amenaza en el ámbito de la seguridad internacional en la esfera global. Muchos factores contribuyeron a este peligro, de los cuales el más importantes fue la intensidad feroz del fenómeno del terrorismo, asociado principalmente con la actividad de los grupos terroristas islámicos, sobre todo de $\mathrm{Al}$ 
Qaeda.El apogeo de este tipo de terrorismo se materializó el 11 de septiembre del 2001 en forma del atentado terrorista contra el World Trade Center en Nueva York. El ataque más espectacular de tales fánaticos religioso en Estados Unidos tuvo implicaciones internacionales muy graves. El primer movimiento de Estados Unidos fue la organización de un frente internacional de lucha contra el terrorismo islámico, dentro del cual el 7 de octubre del 2001 se llevó a cabo la invasión de Afganistán, gobernado por talibanes, anfitriones del líder de Al Qaeda, Osama Bin Laden. EI ataque de los extremistas sobre Estados Unidos resultó también con el crecimiento del número de los atentados terroristas en varias partes del mundo, llevados a cabo por las organizaciones terroristas de ascendencia islámica. Otro acontecimiento extremadamente importante, que ejerció una influencia en la seguridad regional y global, fue la ola revolucionaria conocida como primavera árabe, que tuvo lugar en varios países árabes, entre ellos Túnez, Argelia, Libia y Egipto y, en menor medida, Bahréin. En el marco de esta revuelta, el objetivo de los revolucionarios fue la introducción de cambios amplios, destinados a la democratización de la región. La primavera árabe tuvo también una influencia destacada en la ya muy complicada situación social donde desde el año 2011 persistía la guerra civil. El conjunto de los acontecimientos relacionados con las operaciones militares en Medio Oriente, la guerra civil en Siria, y así mismo la gran dedicación en estos acontecimientos por parte de los grupos terroristas ocasionó que el sistema de seguridad militar mundial, más o menos sólida hasta aquel momento se viera amenazado. El único factor importante que influyó en estas circunstancias fue la involucración en las operaciones militares en el territorio de Siria e Iraq de las fuerzas globales: Estados Unidos y de los países aliados, Rusia, Turquía, Irán, así como de varios grupos armados, empezando por los rebeldes que están luchando por una Siria libre, y terminando con la creación del Estado Islámico. Esta situación causó un importante crecimiento de las amenazas militares a nivel internacional, fue y sigue siendo el conflicto en Siria, el que está focalizando la lucha entre los chiitas, alauitas y la mayoría suní. Cada una de las partes, apoyada por sus respectivos aliados, actualmente ya tiene tanto armamento, que incluso la retirada de todas las fuerzas internacionales no sería suficiente para terminar el conflicto. El presente artículo se centra tanto en la identificación del origen del conflicto, como en la representación de los intereses de los respectivos países participantes. El elemento más importante del 
trabajo es el intento de demostrar la tesis, según la cual el estado de la seguridad militar en el mundo está indivisiblemente relacionado con la situación actual en Siria e Iraq.

\section{Orígenes del Conflicto Sirio}

Las causas del grave conflicto en Siria son extremadamente complejas. Sus raíces se remontan al sistema social, creado por el actual presidente del país Bashar AlAssad, quien sucedió a su padre Haféz Al-Assad, fallecido en el año 2000. El sistema social y político actual en Siria está basado sobre todo en el gobierno de los militares. Assad fundamenta su poder en las instituciones públicas estructuradas de forma jerárquica, conectadas con el partido Baaz y otros partidos relacionados con este grupo. Estos grupos se integraban dentro del Frente Nacional Progresista al igual que con el servicio de seguridad y las tropas del ejército. Bashar Al-Assad en efecto estableció un régimen autoritario basado por completo en el ejército mencionado anteriormente. Los elementos más destacados de este régimen son el servicio de seguridad y el ejército, constituyendo una fuerza cuyo objetivo es la protección del estado de Bashar Al-Assad ${ }^{3}$.

La función del presidente Bashar Al-Assad en Siria es equivalente al poder ejecutivo. La concentración de este poder en las manos del presidente permite básicamente que la toma de decisiones relacionadas con las cuestiones de la gobernanza sea totalmente autónoma. Bashar Al-Assad ostenta el derecho, tanto de diseñar la política del país, como de ponerla en práctica; puede nombrar y cesar a los respectivos ministros, tomar decisiones acerca de la declaración del estado de guerra y del estado de excepción. Al mismo tiempo fue el Comandante Supremo de las Fuerzas Armadas de Siria, y podría también, indicando la causa promulgar la disolución de las Cortes de la Asamblea del Pueblo. Queda claro, por tanto, que las facultades del Bashar Al-Assad le otorgan el poder sobre el Estado, sus instituciones

\footnotetext{
${ }^{3}$ Lukasz, Fyderek, Pretorianie i technokraci w reżimie politycznym Syrii, , Księgarnia Akademicka, Cracovia 2011, p. 71.
} 
y organismos. Este poder fue y sigue siendo ejercido por el presidente de Siria con la ayuda del partido Baaz ${ }^{4}$.

Bashar Al-Assad al suceder a su difunto padre adoptó también el sistema del nombramiento de determinados y expuestos puestos. Así por ejemplo, los puestos decisorios eran ocupados por los alauitas miembros de un grupo religioso, que tenían la total confianza del fallecido Haféz Al-Assad. Resulta interesante y muy poco común en la política interna de otros países, ya que de hecho los alauíes formaban un grupo social que comprendía tan solo al 11 por ciento de la población. Sin embargo, constituyeron un elemento fundamental del poder. La confianza depositada en los alauíes por parte de los gobernantes, con el presidente al frente, se basaba en su devoción religiosa y su lealtad tribal. Los alauitas son un grupo religioso reducido, también conocidos como nusayri cuyo tamaño se estimó en 1,95 millones ${ }^{5}$.

Las fuerzas armadas de Bashar Al-Assad fueron utilizadas en la lucha periódica contra las revueltas que estallaban en Siria. En el periodo anterior de este país se utilizaron para reprimir de forma sangrienta las revueltas sociales durante los años setenta y ochenta del siglo XX. Defendiendo la posición del presidente Bashar Al-Assad, el ejército al mismo tiempo desarrollaba las estructuras de los servicios especiales, entre ello el servicio de inteligencia y de contraespionaje, para a través de sus actuaciones influenciar la situación interna, regional e internacional. Se fundaron unidades especiales a las que se encomendó la tarea de creación de una barrera de seguridad para el poder gubernativo en caso de posibles revueltas sociales. La policía política funcionaba a la perfección ${ }^{6}$.

El ejército sirio, justo antes del alzamiento en el año 2011 se evaluaba como la potencia militar en la región. Es cierto que la mayoría del armamento se basaba en la producción rusa, sin embargo, el ejército contaba con 300000 soldados, equipados con varios millares de tanques, cañones y vehículos blindados, en torno a 1000 aviones y helicópteros. Siria contaba con un arsenal de armas químicas lo que

\footnotetext{
${ }_{5}^{4}$ Ibidem, pp.74-75.

5 Religia - odłamy muzułmanów - alawici, disponible en http://syria.pl/cms/index.php?option=com_content\&task=view\&id=104\&ltemid=27, consultado el 29 de septiembre de 2016.

${ }^{6}$ Fyderek, Łukasz, op. cit., pp.102-103.
} 
quedó confirmado en el año 2013 al utilizarse en diciembre contra los rebeldes, así como en agosto del 2016, cuando desde los helicópteros se lanzaban recipientes con cloro en los territorios ocupados por la oposición ${ }^{7}$.

La sociedad siria cada vez más protestaba contra la situación del país, la cual influía en el empeoramiento de las condiciones de vida. Una de las causas indirectas que incrementó el deterioro de la situación económica fue sin duda el sistema autoritario de Bashar Al-Assad. En el 2004 al régimen se le impusieron diversas sanciones cuyas causas principales fueron el apoyo de Ásad a las organizaciones terroristas y la producción de armas químicas. Con independencia de esto, la segunda causa del mal estado de la economía siria fue ocasionada por las operaciones llevadas a cabo por los servicios del presidente contra las fuerzas gubernamentales iraquíes cuyo objetivo era recuperar la estabilidad del país ${ }^{8}$.

A la mala situación económica y política del país se superpuso el gran descenso de la extracción de petróleo. Además Siria de forma cíclica fue atormentada por numerosas sequías, que causaron una importante disminución de la producción total de cereales. Aunque hasta el periodo 2010-2011 Siria fue autosuficiente en cuanto a la producción de alimentos, en los años mencionados fue necesaria la importación de trigo para cubrir las necesidades internas. En el periodo 2012-2013 en Siria se produjo una sequía catastrófica que devastó los campos de cultivo. Cientos de miles de personas, sobre todo población rural, empezaron a trasladarse a las regiones costeras ocupadas en su mayoría por los alauitas. Las tensiones entre suníes y alauitas se intensificaron. La situación interna del país se agravaba, se organizaban numerosas protestas y manifestaciones que eran violentamente reprimidas por el ejército y la policía. Durante estas manifestaciones

\footnotetext{
${ }^{7}$ S/a, "Spadły pojemniki z trującymi gazami”. Zemsta za rosyjski helikopter?, TVN24, 2 de agosto de 2016, disponible en http://www.tvn24.pl/wiadomosci-zeswiata,2/syria-atak-chemiczny-w-miejscu-gdzie-zestrzelono-smiglowiecrosjan,665495.html, consultado el 28 de septiembre de 2016.

${ }^{8}$ S/a, Kryzys w Syrii: wojna domowa, globalne zagrożenie, autorem artykułu jest Ban Ki-moon, Sekretarz Generalny ONZ, UNIC Warsaw, 23 de junio de 2014, disponible en http://www.unic.un.org.pl/sg---inne-wypowiedzi/kryzys-w-syrii:-wojna-domowaglobalne-zagrozenie---artykul-sg/2583, consultado el 28 de septimebre de 2016.
} 
fallecieron varios civiles. Esto fue el resultado del uso por parte de las fuerzas del presidente de munición real contra los manifestantes ${ }^{9}$.

Para finalizar la parte de las consideraciones en las que de forma muy sucinta se intentó presentar las causas del conflicto armado en el que actualmente están involucrados varios países y organizaciones, entre ellas algunas de carácter terrorista, sería oportuno mencionar los factores más importantes contribuyentes a su expansión: la siniestralidad climática causada por las sequías cíclicas en el territorio sirio; la influencia de las sanciones económicas impuestas por el apoyo al terrorismo y producción de armas de destrucción masiva, una crisis muy grave relacionada con las limitaciones de la extracción de petróleo y también, los crecientes problemas financieros del país. Independientemente de las dificultades económicas sirias, el causante de la situación interna de este país fue y sigue siendo el régimen autoritario de Bashar Al-Assad. Parece ser igual de importante que la toma de las acciones por parte de la sociedad siria tales como alzamientos o manifestaciones, fueron incentivadas por la primavera árabe. Probablemente, en menor medida pero en un momento crítico para el desarrollo de la situación en Siria se sumó la tensión basada en la religión y las diferencias étnicas, manifestándose incluso en la lucha por la influencia entre el privilegiado grupo de alauitas y suníes.

\section{III. influencia del conflicto Sirio en el Estado de la Seguridad Militar Mundial.}

Para hacer frente a la problemática resultante de la posibilidad de la influencia del efecto del conflicto sirio sobre el estado de la seguridad internacional, es necesario presentar la imagen del conflicto en Siria, y sobre todo la característica de las organizaciones que forman su parte.

Prácticamente cinco años de operaciones militares en territorio sirio causaron, que el conflicto se extendiese a la zona de Iraq, como consecuencia de la trasmisión al territorio de este país de las operaciones militares por el llamado Estado Islámico. En este trabajo dado que la palabra "Estado" se refiere sobre todo a los organismos estatales, de los cuales la mayoría tiene un fundamento democrático, en lugar de

\footnotetext{
${ }^{9}$ Protesty w Syrii. Wojsko krwawo tłumi powstanie, 31 de julio de 2011, http://www.polskieradio.pl/5/3/Artykul/411380,Protesty-w-Syrii-Wojsko-krwawo-tlumipowstanie, consultado el 28 de septimebre de 2016.
} 
esta denominación a partir de este momento se utilizará la de "Organización del Estado Islámico" (OEI), este nombre fue adoptado y está en uso por la revista francesa "Le Monde diplomatique"10.

Al conocer los sujetos que participan en la guerra civil en Siria, entenderemos porqué el título de este trabajo es el que es. A mi juicio, el conflicto armado en Siria es, desde luego, una guerra de todos contra todos. La oposición armada contra Assad está formada por 100 grupos, a menudo de corrientes políticas diametralmente opuestas o credos diferentes. La orientación política o religiosa de los diferentes grupos opositores abarca desde grupos democráticos, o liberales, hasta el islam radical. El punto en común de estos grupos reside en la determinación de las acciones destinadas a apartar del poder a Bashar Al-Assad. A pesar de tener definido de forma clara el objetivo común, con bastante frecuencia se producen enfrentamientos entre estos grupos ${ }^{11}$.

Entre los grupos de oposición más importantes destacan: el Ejército Libre Sirio, el Frente Islámico y el Frente Al-Nusra.

1. El Ejército Libre Sirio (ELS) se deriva de un grupo de desertores del ejército de Assad que participaron en marzo del año 2011 en la operación represiva de una manifestación durante la cual decidieron unirse a los manifestantes. Los acontecimientos, en los que se llevó a cabo la deserción en la ciudad Daara fueron el comienzo de la guerra que está actualmente en curso. Inicialmente, este grupo constituía la fuerza más elemental combatiente contra el ejército gubernamental de Assad. En la actualidad, es una unión de grupos pequeños, que llevan en sus banderas tanto eslóganes democráticos como los relacionados con la moderada forma de islam. ELS recibió y sigue recibiendo apoyo por parte de Turquía y de otros países occidentales. La ayuda de estos países, despertó los antagonismos que se reflejaban en forma de ataques a ELS por fuerzas como la OEI, o bien, Al Qaeda. Por lo tanto, ELS desde hace dos años está colaborando estrictamente con tropas kurdas, que actúan en el norte del país contra OEl.

\footnotetext{
10 Julien, Théron, Rywalizacja Al-Kaidy z Państwem Islamskim, http://mondediplomatique.pl/LMD108/index.php?id=1_4, consultado el 29 de septiembre de 2016. ${ }^{11}$ Górzyński, Oskar, Syria, czyli wojna wszystkich ze wszystkimi. Preludium do wojny światowej?, 23 de septiembre de 2015, http://wiadomosci.wp.pl/kat,1356,title,Syriaczyli-wojna-wszystkich-ze-wszystkimi-Preludium-do-wojnyswiatowej,wid,17923206, wiadomosc.html, consultado el 27 de septiembre de 2016.
} 
2. El Frente Islámico (FI) es el mayor grupo que asocia grupos de carácter islamista originarios de Siria. De entre ellos el más numeroso es Ahrar al-Sham (Movimiento Islámico de los Hombres Libres del Levante), considerado como el más eficiente dentro de la oposición combatiente en Siria. Los miembros de este grupo están acusados de crímenes de guerra cometidos en el año 2013 durante el ataque a pueblos en la provincia de Latakia, que estaban a favor del gobierno en Damasco. De acuerdo con las comprobaciones de servicio de inteligencia resulta que este grupo cuenta con el apoyo de Turquía y Qatar. Los países occidentales rechazaron la propuesta de cooperación con IF incluso en la lucha contra OEI.

3. El Frente al-Nusra, actualmente Jabhat Fateh al-Sham, es un grupo constituido por una fracción o tal vez una filial de Al Al Qaeda. Tanto en la evaluación de los analistas, como de los expertos en cuestiones del Medio Oriente es uno de los grupos mejor armados, que cuenta con las estructuras mejor organizadas. Su objetivo es la expulsión de Assad, sin embargo, en su lugar están planeando constituir en Siria el emirato que será gobernado basándose en la sharia. A pesar de eso, el Frente Al-Nusra desde el 2013 se encuentra inmerso en la lucha contra OEL. Este grupo está considerado como una organización terrorista, pero no se dispone de datos acerca de quién realmente está apoyando sus acciones y prestando asistencia en la compra y las entregas de armamento $^{12}$.

Cabe destacar a la Organización del Estado Islámico (OEI), la que es tercera fuerza en cuanto a su tamaño después del ejército de gobierno de Assad y la oposición armada de la guerra en Siria. Es la organización de mayor peso de carácter islamista. Gobierna en los territorios ocupados en el territorio de Siria oriental y en el noroeste de Iraq, lugar del que están siendo en su mayoría expulsados por las tropas iraquíes y de la coalición de Países Occidentales bajo el liderazgo de Estados Unidos. Esta organización está dirigida por Abu Bakr alBaghdadi, quien en julio del 2014 declaró en la ciudad de Mosul la creación del Estado Islámico en forma de califato. Asimismo, se autoproclamó califa, aceptando el nombre Ibrahim con lo que se convirtió en su opinión en el líder del mundo musulmán ${ }^{13}$.

\footnotetext{
12 Ibidem.

13 Ibidem.
} 
Las operaciones llevadas a cabo por las tropas leales al gobierno iraquí y los elementos de las fuerzas armadas de los países aliados que operan en este país, están preparando una gran ofensiva sobre Mosul, todavía ocupada por OEI. Los informes de los medios de comunicación señalan que el ejército estadounidense tomó medidas para liquidar a los principales líderes de OEI. Durante el mes pasado, 18 miembros importantes de OEI fueron asesinados como resultado de los bombardeos de posiciones yihadistas ${ }^{14}$.

El ataque planeado sobre Mosul despertó el pánico entre los yihadistas de OEI. Están preparando la defensa, cuyo objetivo es conducir la batalla hasta la última gota de sangre. Estas acciones son un intento de conservación de los territorios ocupados en Iraq, lo que tiene como finalidad permitir el funcionamiento continuo y el refuerzo de OEI en este país. Dentro de la OEI en Mosul se están realizando varias detenciones y ejecuciones, además de otros que se fomentan debido al miedo dentro de las filas de la agrupación. Las estructuras de OEI prácticamente no funcionan. La ofensiva sobre Mosul está planeada para octubre de 2016. Están aumentando los actos de resistencia contra OEI en el mismo Mosul. En las murallas aparecen proclamas en contra de los yihadistas, por ejemplo la letra "m", que deriva de la palabra mukawama, la que significa "resistencia". La OEI está preparando trincheras alrededor de la ciudad y construyendo defensas de hormigón entre los barrios, esto anticipa una batalla sangrienta por el último bastión de ese tamaño de esta organización ${ }^{15}$.

Las principales fuerzas combatientes en el bando de Bashar Al-Assad, están integradas por alauitas y chiitas. Estas fuerzas disponen de unidades regulares terrestres, así como aviación, cuentan con el apoyo de las tropas voluntarias del partido Baaz. A los principales enemigos de Assad junto con la oposición autóctona pertenece la Organización del Estado Islámico. En septiembre de 2015 el presidente de Siria obtuvo gran apoyo por parte de uno de sus fieles aliados, es decir, la Federación Rusa, cuyas acciones se concentraron sobre todo en los ataques aéreos

\footnotetext{
${ }^{14}$ Przemysław, Henzel, Koalicja szykuje wielkie uderzenie w ISIS. Zapadła ważna decyzja armii USA, 30 de septiembre de 2016, http://wiadomosci.onet.pl/panstwoislamskie/fwxg4, consultado el 30 de septiembre de 2016.

${ }^{15}$ S/a, „Panika i rebelia w sercu kalifatu - Dżihadyści szykują desperacką obronę”, 23 de septiembre de 2016, http://www.tvn24.pl/wojna-w-iraku-dzihadysci-szykujaobrone-mosulu,678483,s.html, consultado el 28 de septiembre de 2016.
} 
sobre los puntos ocupados por las fuerzas de la oposición siria. Las garantías del presidente V. Putin, de que Rusia a través de su contribución al conflicto en Siria, está tomando medidas con el objetivo de la lucha con los yihadistas de OEI es una mentira preparada para las necesidades de la comunidad internacional. La ayuda por parte de Rusia e Irán definitivamente mejoró la situación en la línea de combate de Assad con los rebeldes.

Como una de las consecuencias del apoyo prestado a Ásad podemos mencionar la reconquista por las leales a su fuerzas, parte de la ciudad Alepo, ocupada por la oposición combatiente ${ }^{16}$.

Irán es otro aliado de Assad y probablemente es uno de los aliados más valiosos para el régimen sirio. Desde hace algunos años en el territorio de Siria están luchando los soldados pertenecientes al Cuerpo de la Guardia Revolucionaria Islámica. Diversas fuentes indican que en los últimos tres años fallecieron 18 oficiales iraníes. Probablemente llevaban parte del asesoramiento militar. Se puede definir a los soldados iraníes que actúan en Siria al igual que los Rusos combatientes en Ucrania como "personas que están de vacaciones". Irán envío y sigue enviando sus soldados a la región de Alepo donde están aconteciendo las operaciones militares más graves ${ }^{17}$.

El siguiente jugador en el conflicto sirio es Hezbolá, incluido en la lista de organizaciones terroristas. Esta organización fue fundada y financiada por Irán y Siria, su sede se encuentra en el territorio de Líbano, donde después de la retirada de las tropas israelíes de este país en el 2000, emprendió la actividad política, para así mismo en las elecciones en el año 2005 conseguir el 11 por ciento de los puestos en el parlamento libanés. Sin embargo, es una organización con raíces terroristas, que está materializando los objetivos de la política iraní en el mundo. Los guerreros de Hezbolá están luchando en Siria apoyando a Bashar Al-Assad, realmente representando en este país los intereses de Irán; en efecto Irán, al igual que los rusos, está intentando encubrir su contribución en el conflicto sirio ${ }^{18}$.

\footnotetext{
${ }^{16}$ Oskar, Górzyński, op. cit.

17 Ibidem.

18 Oskar, Górzyński, op. cit.
} 
La Federación Rusa tras una larga fase de estancamiento en política internacional, causada por la invasión militar de Ucrania y la anexión de Crimea, fue aislada de la gran política en el mundo, por lo tanto los rusos por medio de la intervención en el conflicto militar en Siria intentaron recuperar su fuerte posición en el ámbito de la política internacional. La declaración de los rusos sobre la lucha en el territorio de Siria con los yihadistas con la OEI ya en su fase inicial se alejaba de la verdad. Los primeros ataques aéreos, que comenzaron el 30 de octubre del 2015, se llevaron a cabo en dos provincias de Siria, Homs y Deir Mama, situadas lejos de las posiciones reales de la OEI. Parece, algo que fue confirmado a posteriori, que los rusos centraban sus acciones en el bombardeo de las posiciones de las tropas armadas de la oposición siria. Es interesante el hecho, de que ya después del comienzo de la invasión militar de Rusia en Siria, las tropas de la OEl "atacadas por la aviación rusa" consiguieran nuevos territorios en la región de Alepo $^{19}$.

Los kurdos forman importantes fuerzas armadas, que en Siria están empezando la batalla contra las tropas de $\mathrm{OEI}$. Los kurdos que están luchando en el territorio de este país, están habitando la región qué está totalmente bajo su control- la obtuvieron a consecuencia de sus acciones en contra del ejército del gobierno de Ásad. Los kurdos son la parte que está con más frecuencia atacada por las fuerzas de Assad, el Frente Al-Nusra y también por OEI. En los últimos meses están combatiendo de forma intensa por las tropas turcas, las que en febrero del año 2016 se involucraron en la operación militar en Siria. Turquía con el miedo a que los kurdos tras finalizar el conflicto sirio no continúen la lucha por la liberación total y autonomía en su territorio, está lanzando ataques aéreos sobre las tropas kurdas, y recientemente entró con sus fuerzas terrestres al territorio de Siria $^{20}$.

Recapitulando las consideraciones acerca de la situación de seguridad en Siria, cabe destacar que la salida perfecta sería la solución del conflicto sirio por las fuerzas que están directamente comprometidas, sin ningún tipo de intervención exterior. Aunque resulta evidente, que el recrudecimiento de la lucha, destacando el

19 Rosyjskie naloty w Syrii, http://www.tvn24.pl/raporty/rosyjskie-naloty-w-syriirosjanie-bombarduja-syrie,1012, consultado el 28 de septiembre de 2016.

${ }^{20}$ Turcja atakuje Kurdów w Syrii. Zmasowany ostrzał artyleryjski, PolskieRadio.pl, 14.02.2016, http://www.polskieradio.pl/5/3/Artykul/1582422\%2CTurcja-atakujeKurdow-w-Syrii-Zmasowany-ostrzal-artyleryjski, consultado el 29 de septiembre de 2016. 
uso de armas químicas, obligó a que se implicasen fuerzas externas. En la actual situación se debe reconocer como imposible que la guerra civil en Siria se pueda terminar de forma pacífica por los propios sirios. Por lo tanto, la participación de los países árabes, incluyendo parcialmente Arabia Saudita, Qatar, Irán y Turquía, que desde hace años están luchando por la influencia y dominación en Damasco, parece estar justificada. Por otro lado, en la guerra participan países considerados como potencias mundiales, tanto en su dimensión económica, como militar: Estados Unidos, Rusia, China y algunos países europeos. Parece que ninguna de las partes del conflicto que representan las fuerzas externas pueda elaborar una posición común, para así, de manera pacífica dar lugar a la conclusión de las acciones en Siria. En realidad, las potencias mundiales están manteniendo en Siria una lucha por las influencias geopolíticas en Damasco, que está constituyendo una puerta al Medio Oriente. Se está afirmando, que el que conseguirá la mayor influencia en Damasco y Líbano, será el encargado de definir la política del Medio Oriente - y de eso trata el juego político de los grandes de este mundo.

\section{EI Impacto del Conflicto Sirio en el Estado de la Seguridad Social a Nivel Internacional.}

La seguridad social es un concepto que comprende varias cuestiones desde el funcionamiento del ser humano como parte de la sociedad. Entre ellas podemos destacar sobre todo la cuestión de la existencia humana a nivel que garantice una vida digna, es decir, la seguridad material, bienes de consumo e incluso culturales, sanidad y muchas más. La seguridad social en varias regiones del mundo varía repetidamente. Así por ejemplo, sus niveles en los países de la Unión Europea y África son diametralmente opuestos. La definición científica de la seguridad social dice que es:

Básico, imprescindible factor del papel del país que debería ser modelado de forma que permita asegurar a sus ciudadanos el mínimo de la seguridad social, que permita la existencia humana- del ciudadano y su 
familia en el nivel que le permita realizar sus propósitos, planes suyos y de su familia en un determinado ámbito de funcionamiento ${ }^{21}$.

Hoy en día en la percepción de la sociedad, como una amenaza crucial se considera sobre todo los riesgos económicos, políticos, así como militares. El menor desequilibrio de la seguridad en estas zonas en seguida tiene repercusiones en el decrecimiento del sentido de la seguridad de la sociedad en la mayoría de los países de la región, donde dicho decrecimiento sucede. La inseguridad, conflictos armados o finalmente guerras como la de Siria, intensifican la disminución del sentido de la seguridad de los ciudadanos. En la actualidad podemos observar en el mundo una tendencia indicando el decrecimiento de la seguridad social de los ciudadanos de varios países. Principalmente se ven afectados países de la Unión Europea, igual que Estados Unidos, Canadá, Australia y países de Medio Oriente y África. En países de Medio Oriente y África este fenómeno adopta una dimensión especial, ya que estas son zonas tradicionales de pobreza y hambruna. Adicionalmente, se enfrentan con las amenazas por parte de los extremistas islámicos, como en Nigeria donde la organización Boko Haram, que produce asesinatos masivos de civiles, anunció también su unión al Califato creado por OEI en el territorio de Iraq y Siria ${ }^{22}$.

En los últimos años observamos un descenso más pronunciado de la seguridad social en los países de la Unión Europea, pero también en los países mencionados anteriormente de fuera de Europa debido a la migración de millones de personas, de Siria inclusive, donde desde el 2011 está el conflicto armado. En Siria, durante la guerra, perdieron la vida 250000 personas, mientras que 7 millones emigraron. El destino de los refugiados de las zonas afectadas por el conflicto en Siria y otros países del mundo, entre ellos africanos, fueron países ricos de la Unión Europea, pero también Estados Unidos, Canadá y Australia. La actual crisis de refugiados se comenzó a considerar en categorías de una catástrofe natural, para la cual ninguno de los países de la Unión Europea tanto de forma individual, como la Unión Europea en su conjunto, como organización, se había preparado. La ausencia de planes, así

21 Ryszard, Zięba, Pojęcie $i$ istota bezpieczeństwa państwa $w$ stosunkach międzynarodowych, "Sprawy Międzynarodowe" 1989, núm. 10, p. 50.

${ }^{22}$ Wojciech, Jagielski, Boko Haram w Nigerii. Nie widać końca wojny z islamistami, 21 de junio de 2015, http://wiadomosci.wp.pl/kat,1356,title,Boko-Haram-w-NigeriiNie-widac-konca-wojny-z-islamistami,wid, 17651599, wiadomosc.html?ticaid=117d54, consultado el 28 de septiembre de 2016. 
como la imposibilidad de prestación de ayuda básica a cientos de miles de refugiados, como sucedió en el caso de los países balcánicos, fueron el inicio de los actos de agresión por parte de algunos países. Estos países sencillamente no disponían de los recursos técnicos y materiales, para poder absorber los flujos migratorios a los que se enfrentan. Se puede decir, que Europa está al borde de una catástrofe, frente a la que faltaron soluciones que se puedan adoptar en un corto periodo de tiempo ${ }^{23}$.

Las operaciones de guerra en Siria o en Afganistán, así como en África, están creando grandes grupos de refugiados o inmigrantes. Con inmensa sorpresa, pero también tristeza, despiertan opiniones que vienen de todo el mundo, acusando a los países de la Unión Europea de la muerte de miles de personas ahogadas durante sus travesías a través del Mar Mediterráneo. No obstante, estos países no son la causa de esta migración. La migración puede ser vista como una tragedia de miles de personas de los países en cuyos territorios tienen lugar operaciones militares o bien, las que desde años se consideran zonas de pobreza, como por ejemplo Bangladés, Etiopía, Eritrea, Pakistán y otros países postcoloniales, que durante décadas no tomaron las debidas medidas para asegurar a sus ciudadanos un nivel de vida aceptable. Los gobiernos de estos países aceptan que en sus zonas funcionen las organizaciones extremistas islamistas, que organizan trayectos de refugiados, obteniendo elevadas ganancias. Por su parte Europa no es capaz, con ningún tipo de medios pacíficos, controlar las olas de emigrantes y refugiados, en muchas ocasiones derivadas a Europa con el permiso de Turquía. No cabe duda que Rusia tiene una influencia cada vez mayor en las olas de emigrantes sirios que se están acumulando, que al involucrarse en la guerra siria, bombardea posiciones consideradas por si misma como rebeldes, pero con bastante frecuencia habitadas por la población civil- abandonada allí adrede por los que luchan codo con codo con el régimen de Bashar al-Ásad, para su uso como escudos humanos. La intensificación de los bombardeos rusos, da lugar a la huida de esta población,

${ }^{23}$ Andreas, Unterberger, Europa i katastrofa migracyjna. Jedyne wyjście: uczyć się od Australii, 2016, disponible en http://www.miastowroclaw.pl/index.php/prolife/item/6854-europa-i-katastrofa-migracyjna-jedyne-wyjscie-uczyc-sie-od-australii, consultado el 28 de septiembre de 2016. 
principalmente a Turquía, allí es donde a través de los campos de refugiados se dirigen a Europa ${ }^{24}$.

Aunque Europa no sea culpable de las muertes de miles de emigrantes y refugiados, no obstante, su política de inmigración de bajo nivel y la corrección política al problema que se hace cada vez más grave dio lugar a que los campos de acogida de los emigrantes, no recibieran ningún tipo de señales claras y firmes por parte de la Unión Europea. No se habían aplicado normativas robustas de migración, ni una prohibición absoluta a la entrada de los emigrantes al territorio de la Unión. Según los datos publicados en los medios de comunicación cerca de 550000 emigrantes en Alemania, aunque no hayan obtenido el permiso de residencia, no han sido expulsados y siguen permaneciendo, ya ilegalmente, en el territorio de este país. Esto debe interpretarse como la debilidad de la administración responsable de la política de migración. Lo peor aún es, que el mismo criterio en cuanto a la migración es utilizado por los responsables de la Unión Europea. Esto podría demostrar la vulnerabilidad del sistema, pero sobre todo la temerosa postura de las personas dirigentes de la administración de la Unión. ${ }^{25}$

La situación en los países de Unión Europea y varios países del mundo, despertada por emigrantes, en gran medida contribuyen a la gran disminución de la sensación de seguridad de estas sociedades. El declive se observa principalmente en el ámbito de la seguridad física de los ciudadanos y sus familias. Aumentan también las preocupaciones por el descenso de la posición económica, proveniente del miedo a la pérdida de puestos de trabajo. Resultó que las preocupaciones de los ciudadanos de los países europeos están plenamente justificadas, como demostraron los incidentes con la participación de varios emigrantes en algunas ciudades en Alemania, como es el caso de la Nochevieja del 2015-2016 donde habían agredido sexualmente a varias decenas de mujeres jóvenes, robado bolsos, dispositivos móviles o joyas. La sociedad alemana se vio estupefacta. Dichas

\footnotetext{
24 Ibidem.

${ }^{25}$ „Bild”: 550 tys. imigrantów, którym odmówiono azylu, zostało w Niemczech, 22 de septiembre de 2016, http://info.wyborcza.pl/temat/wyborcza/imigranci+w+niemczech, consultado el 28 de septiembre de 2016.
} 
agresiones, en total 160, tuvieron lugar en Colonia y Hamburgo. Sorprendente fue el silencio por parte de las autoridades sobre lo sucedido ${ }^{26}$.

Independientemente de la disminución de la sensación de la seguridad social, causada por la crisis migratoria de las zonas afectadas por las operaciones militares en Oriente Próximo al territorio de los países de la Unión Europea y otros países del mundo, hay que señalar otros fenómenos igual de negativos y peligrosos. Relacionado con la aparición y activación de movimientos nacionalistas, cuyos eslóganes nada se alejan de los eslóganes nazis. Cabría esperar que la Unión tarde o temprano solucionará el problema de la migración, pero más grave todavía será el problema de la reorientación de grandes grupos sociales de corte nacionalista.

Un elemento de especial importancia influyente en la drástica disminución de la sensación de la seguridad de las sociedades, sobre todo en Europa, fueron también los atentados terroristas, cometidos en Francia, Bélgica y Alemania. En los atentados en París y en Saint-Denis perdieron vida más de 100 personas, y cientos de personas fueron heridas. Los autores de estos actos fueron terroristas islámicos con ciudadanía francesa ${ }^{27}$.

Ejemplos de los atentados en Francia, como los posteriores en Bélgica o Alemania completamente justifican la mayor preocupación de los ciudadanos de estos países relacionados con el asentamiento de los emigrantes de países del Medio Oriente o África. Tras ataques terroristas en países que aceptan cientos de miles de emigrantes, en el caso de Alemania son alrededor de 1,5 millones, sus residentes cada vez están más en contra de la emigración. Podemos observar la evaluación de las opiniones políticas en Alemania, Austria, Francia y países de Europa del Este, entre ellos Hungría, Polonia o Eslovaquia. Allí donde la política bruscamente toma la dirección de la derecha extrema, lo que es un fenómeno muy peligroso, porque separa las sociedades, fomentando conflictos internos dentro de las mismas.

${ }^{26}$ Pierwsi zatrzymani za ataki na kobiety. Policja przyznaje: zbagatelizowaliśmy zagrożenie, 7 de enero de 2016, http://www.tvn24.pl/wiadomosci-zeswiata,2/napasci-na-kobiety-w-niemczech-pierwsze-zatrzymania-policji,608630.html, consultado el 28 de septiembre de 2016.

${ }^{27}$ Zamachy terrorystyczne w Paryżu. Wybuchy i strzelaniny. Sa ofiary, 13 de noviembre de 2015, http://www.test.tvs.pl/informacje/zamachy-w-paryzu-13-11wybuchy-i-strzelaniny-sa-ofiary-wideo, consultado el 29 de septiembre de 2016. 


\section{Conclusiones}

En resumen, las precedentes reflexiones acerca de la influencia del conflicto en Siria al estado de la seguridad social y militar nos permiten obtener varias conclusiones.

En primer término, debe notarse que el conflicto sirio ha ido aumentando durante muchos años, careciendo de la reacción por parte de los protagonistas del escenario económico mundial. Excepto Estados Unidos, que impuso a Siria diversas sanciones debido a su apoyo a las organizaciones terroristas y la producción de armas químicas. Ningún otro país ha decidido emprender este tipo de actos.

De igual forma Rusia, considerada como la segunda potencia militar mundial, que mantiene relaciones con Siria que datan de los tiempos de Hafés al-Ásad, desde hace muchos años fue consciente que el régimen del presidente de Siria Bashar AlAssad llegaría a la situación en la que se vería obligado a ceder si no cambiaba su estilo de gobernanza. Rusia fue y sigue siendo el socio principal de Siria en el campo del suministro en armas. La decisión de participar en la guerra en Siria, fue justificada con el deseo de ayudar al gobierno legítimo de este país que solicitó el apoyo ruso en la lucha contra OEI. Maniobras reales del ejército ruso, resultaron ser los bombardeos de zonas fronterizas con Turquía habitadas por turcomanos, así como de las zonas ocupadas por el ejército de la oposición al régimen sirio, en la región del centro urbano más grande- Alepo. El bombardeo al mismo tiempo de los objetivos civiles, está visto por la sociedad internacional como crímenes de guerra. No obstante, Rusia no está tomando ninguna medida, para terminar de forma pacífica el conflicto en Siria, juntándose con la coalición de países occidentales y fuerzas sirias para atacar la OEI y terminar destruyéndola.

Debe también destacarse que flujos migratorios millonarios, que atravesando Turquía y los Balcanes inundan Europa y otros países en el mundo, se convirtieron actualmente en moneda de cambio por Turquía, quien dice que de no llevarse a cabo la exención de visados para sus ciudadanos, en las puertas de Europa se presentara otro millón de emigrantes. Esto podría finalizar incluso en conflictos armados. 
La serie de atentados en el territorio de países de la Unión Europea, Estados Unidos, Iraq y otros países, son señal de que hasta que la sociedad internacional no llegue a un acuerdo y no fuerce un ultimátum a la comunidad islámica internacional, seguiremos siendo testigos de atentados puntuales a los sistemas de valores y culturales de Occidente por parte de las organizaciones terroristas como la Organización del Estado Islámico, Hezbolá u otras.

El aumento notable de la xenofobia y el renacimiento del nacionalismo que en casos extremos puede adoptar forma del fascismo. Falta de educación social, incentivo de las opiniones públicas por nuevos políticos de extrema derecha que están utilizando la situación actual en su propio beneficio, como en Francia, Alemania o Austria, puede ser un mal presagio para la democracia de los países europeos. Finalmente, es muy preocupante el silencio de la iglesia, que está considerada en la mayoría de los países como un pilar, que podría de forma positiva tranquilizar los ánimos, combatir con la xenofobia o advertir ante la vuelta del fascismo.

Por último, debe destacarse que, indudablemente, el conflicto en Siria es tan serio y concentra la participación de tantas fuerzas representantes entre otros, las grandes potencias: Estados Unidos, China y Rusia, que no habrá dudas que está afectando al estado de la seguridad militar a nivel global. Es una fuente del claro declive del sentido de la seguridad social, no solo en los países de la Unión Europea, sino también en Estados Unidos, Canadá, Australia y otros países. 


\title{
VI. Bibliografía, Webgrafía y Fuentes Consultadas
}

DOMINIK, Duda, Terroryzm islamski, wyd. I, Wydawnictwo Uniwersytetu Jagiellońskiego, Cracovia, 2002.

ŁUKASZ, FYDEREK, Pretorianie i technokraci $w$ reżimie politycznym Syrii, Księgarnia Akademicka, Cracovia, 2011.

RYSZARD, ZIĘBA, Pojęcie I istota bezpieczeństwa państwa w stosunkach międzynarodowych, "Sprawy Międzynarodowe" 1989.

\section{WEBGRAFÍA}

\author{
$<$ http://info.wyborcza.pl> \\ $<$ http://monde-diplomatique.pl> \\ $<$ http://syria.pl> \\ $<$ http://wiadomosci.onet.pl > \\ <http://wiadomosci.wp.pl> \\ <http://www.miastowroclaw.pl> \\ <http://www.polskieradio.pl> \\ $<h t t p: / / w w w . t e s t . t v s . p l>$ \\ <http://www.tvn24.pl> \\ <http://www.unic.un.org.pl>
}

Fecha de recepción 02/04/2018

Fecha de aceptación 15/06/2018 